\title{
PENGARUH PENDIDIKAN KESEHATAN TERHADAP KESESUAIAN PEMBERIAN MP-ASI GUNA PENCEGAHAN STUNTING PADA BAYI USIA 6-12 BULAN DI WILAYAH KERJA PUSKESMAS BAITUSSALAM ACEH BESAR
}

\section{The Effect Of Health Education On The Suitability Of Mp-Breast Milk To Prevent Stunting In Infants Aged 6-12 Months In The Work Area Puskesmas Baitussalam Aceh Besar}

\author{
Eva Rosdiana ${ }^{1}$, Febri Yusnanda ${ }^{2}$, Lia Afrita ${ }^{3}$ \\ Universitas Ubudiyah Indonesia Banda Aceh, Akademi kebidanan kholisatur rahmi binjai \\ eva_rosdiana@uui.ac.id, yusnandafebri@gmail.com, lia.afrita@gmail.com
}

\begin{abstract}
ABSTRAK
Usia bayi (0-12 bulan) merupakan masa paling kritis atau disebut dengan periode emas yang merupakan masa dimana terjadinya pertumbuhan dan perkembangan yang sangat pesat, sehingga pada masa ini dibutuhkan gizi yang adekuat untuk menunjang pertumbuhan dan perkembangannya. Kekurangan zat gizi pada bayi dapat mengakibatkan malnutrisi seperti gizi buruk dan stunting.Beberapa penelitian menyatakan bahwa keadaan kurang gizi ini disebabkan oleh beberapa faktor salah satunya kebiasaan pemberian Makanan Pendamping Air Susu Ibu (MPASI) yang tidak tepat. Tujuan penelitian ini adalah untuk mengetahui apakah pemberian pendidikan kesehatan dapat mempengaruhi perilaku ibu dalam memberikan MP-ASI yang tepat dan sesuai ke pada bayinya. Penelitian ini di laksanakan di wilayah kerja Puskesmas Baitussalam Aceh Besar. Rancangan penelitian menggunakan desainquasy eksperiment dengan pendekatan one group pretest and posttest. Hasil pengumpulan data diolah dan dianalisa secara univariate dan bivariate menggunakan uji non parametric yaitu Wilcoxon Signed Rank Test untuk menunjukan adanya perbedaan perilaku ibu dalam memberikan MP-ASI terhadap bayinya sebelum dan sesudah diberikan pendidikan kesehatan. Hasil penelitian diperoleh bahwa kesesuaian pemberian MPASI sesudah diberikan pendidikan kesehatan lebih tinggi yaitu sebesar 3.15 dibandingkan dengan kesesuaian pemberian MP-ASI sebelum diberikan pendidikan kesehatan yaitu sebesar 2.75. Hasil uji statistic diperoleh nilai $\mathrm{p}$-value $=0,031(\mathrm{p}<0,05)$. Kesimpulan ada perbedaan yang signifikans antara kesesuaian pemberian MP-ASI pada bayi usia 6-12 bulan sebelum dan sesudah diberikan pendidikan kesehatan. Diharapkan kepada petugas kesehatan agar dapat memberikan pendidikan kesehatan secara menyeluruh tentang pemberian MP-ASI yang tepat kepada ibu yang memiliki anak usia 6-12 bulan khususnya.
\end{abstract}

Kata Kunci : MP-ASI, Pendidikan Kesehatan, Kesesuaian Pemberian MP-ASI

PENDAHULUAN 
Usia bayi (0-12 bulan) merupakan masa paling kritis atau disebut dengan periode emas yang merupakan masa dimana terjadinya pertumbuhan dan perkembangan yang sangat pesat. Sehingga pada masa ini dibutuhkan gizi yang adekuat untuk mempertahankan berat dan panjang badan yang ideal. Salah satu cara yang efektif untuk mempertahankannya adalah dengan pemberian makanan pendamping air susu ibu (MP-ASI) sejak usia 6 bulan dan dilanjtkan ASI sampai usia 2 tahun (Mufida, dkk, 2015).

Pemberian MP-ASI yang tidak cukup gizi baik secara kualitas dan kuantitas akan berdampak terhadap malnutrisi yaitu gizi kurang/ gizi buruk dan juga terjadinya stunting terutama pada anak di bawah usia 2 tahun. Bila permasalahan gizi ini tidak tertangani secara dini maka anak yang mengalami malnutrisi tersebut menjadi sumber daya manusia yang produktivitasnya rendah dan berisiko mengalami penyakit tidak menular (Arini dkk, 2017).

Status gizi masih menjadi perhatian dunia, publikasi terbaru badan kesehatan dunia (WHO) menyebutkan bahwa kejadian stunting pada anak balita di dunia secara global sebanyak 154,8 juta $(22,9 \%)$. Sedangkan di Indonesia angka untuk status gizi sangat pendek dan pendek (stunting) mencapai 30,8\%. Selain masalah stunting Indonesia juga mengalami masalah gizi lain yang belum tertangani yaitu gizi buruk dan gizi kurang yang mencapai angka 17,7 \% dan nilai ini melebihi ambang batas WHO yaitu 10\% (Riskesdas, 2018).

Gizi buruk juga melanda Aceh dimana angka status gizi buruk dan kurang (underweight) mencapai 24,8\% dengan kabupaten terbanyak adalah Aceh timur (9,4\%). Selain gizi buruk dan kurang Aceh juga menderita status gizi sangat pendek dan pendek (stunting) yaitu sebesar 35,7\%, bahkan angka ini berhasil menjadikan Aceh sebegai peringkat ke-3 nasional untuk kasus stunting pada balita dan Kabupaten/kota tertinggi yang mengalami stunting adalah Subulussalam (47.3\%) (Dinkes Aceh, 2018).

Aceh Besar merupakan salah satu kabupaten di Aceh yang juga memiliki kasus stunting yang tinggi yaitu 31,2\% (Kemenkes RI, 2018) dan berdasarkan data dari Puskesmas Baitussalam Kabupaten Aceh Besar angka kejadian stunting di puskesmas tersebut adalah $26 \%$ (Baitussalam, 2018).

Penyebab kurang gizi pada bayi menurut Devriana (2015) dalam (Darmawan \& Sinta, 2015) tidak hanya disebabkan olek kekurangan pangan, namun juga dapat disebabkan oleh pemberian MP-ASI yang tidak adekuat serta penyapihan yang terlalu cepat. Bahkan hasil penelitian melaporkan bahwa keadaan kurang gizi pada bayi dan anak disebabkan karena kebiasaan pemberian MP-ASI yang tidak tepat dan ketidaktahuan ibu tentang manfaat dan cara pemberian MP-ASI yang benar sehingga berpengaruh terhadap sikap ibu dalam pemberian MPASI.

Dari hasil beberapa penelitian juga menyatakan bahwa keadaan kurang gizi pada bayi dan anak karena kebiasaan pemberian makanan pendamping ASI yang tidak tepat. Ketidaktahuan tentang cara pemberian makanan bayi dan anak serta adanya kebiasaan yang merugikan kesehatan, secara langsung dan tidak langsung menjadi penyebab utama terjadinya masalah kurang gizi pada anak, khususnya pada anak usia di bawah 2 tahun (Direktorat Bina Gizi Kemenkes RI, 2010).

Pendidikan kesehatan pada hakikatnya merupakan suatu kegiatan atau usaha menyampaikan pesan kesehatan kepada masyarakat atau individu.Dengan harapan bahwa dengan adanya pesan tersebut, kelompok atau individu dapat memperoleh pengetahuan tentang kesehatan yang lebih baik. Pengetahuan tersebut pada akhirnya diharapkan dapat berpengaruh terhadap perilaku. Dengan kata lain dengan adanya promosi kesehatan tersebut, diharapkan dapat membawa akibat terhadap perubahan perilaku dari sasaran. Didalam suatu proses pendidikan kesehatan yang menuju tercapainya tujuan promosi (Notoatmodjo, 2011) 
Hasil penelitian yang dilakukan oleh Saleem et al (2014) di Karachi, Pakistan mengenai pengaruh edukasi gizi pada ibu tentang MP-ASI terhadap status gizi anak, yang dilakukan selama 30 minggu, memberikan dampak positif pada penambahan berat badan, tinggi badan dan lingkar lengan atas, serta menurunkan prevalensi stunting dan gizi kurang sebesar $10 \%$ pada kelompok yang diberikan edukasi tersebut. Jika pengetahuan dan perilaku ibu tentang pemberian MP-ASI baik, seimbang dan mencukupi kebutuhan gizi anak maka akan berdampak positif terhadap status gizi anak sehingga dapat mencegah terjadinya malnutrisi.

Salah satu upaya peningkatan status kesehatan dan gizi bayi atau anak melalui perbaikan perilaku masyarakat dalam pemberian makanan merupakan bagian yang tidak dapat dipisahkan dari upaya perbaikan gizi secara menyeluruh.(Direktorat Bina Gizi Kemenkes RI, 2010). Peran petugas kesehatan dalam memberikan penyuluhan MP-ASI juga terbukti dapat meningkatkan pola pikir dan tingkat kepedulian ibu untuk memberikan asupan makanan yang baik, bahkan jika perlu ditambahkan praktik cara pembuatan MP-ASI supaya perilaku pemberian MP-ASI menjadi tepat secara jumlah dan jenisnya (Arini dkk, 2017).

\section{METODDE}

Penelitian ini menggunakan metode penelitian quasi eksperimental dengan rancangan one group pretest and postest design, yang bertujuan untuk menilai pengaruh pendidikan kesehatan terhadap kesesuaian pemberian MP-ASI pada bayi usia 6-12 bulan. Populasi dalam penelitian ini adalah seluruh ibu yang memiliki bayi usia 6-12 bulan yang berjumlah 249 orang dan tersebar pada 20 Posyandu di Wilayah Kerja Puskesmas Baitussalam Aceh Besar . Jumlah sampel adalah 72 orang yang di ambil secara random dengan menggunakan teknik Proportional Simpe Random Sampling. Pengumpulan Data dilakukan pada bulan Agustus sampai dengan September 2020. Teknik pengumpulan data di lakukan dengan wawancara langsung dengan responden yang hadir pada saat dilakukan penelitian.

\section{ANALISA DATA}

Analisa data dilakukan dengan analisa univariat dan Analisa bivariate dengan menggunakan uji non parametric yaitu Wilcoxon Signed Rank Test untuk menunjukan adanya perbedaan perilaku ibu dalam memberikan MP-ASI terhadap bayinya sebelum dan sesudah diberikan pendidikan kesehatan.

\section{HASIL PENELITIAN}

1. Hasil Penelitian

Berdasarkan hasil pengumpulan data yang di lakukan di Wilayah Kerja Puskesmas Baitussalam Aceh Besar dapat di sajikan sebagai berikut :

a. Analisis Data Univariat

a) Praktik Pemberian MP-ASI Sebelum Perlakuan

\begin{tabular}{llrr}
\hline No & Praktik Pemberian MP-ASI & f & \% \\
\hline 1 & Sesuai & 22 & 30.6 \\
2 & Tidak Sesuai & 50 & 69.4
\end{tabular}


Berdasarkan tabel 4.2 menunjukan bahwa dari 72 responden sebelum diberikan pendidikan kesehatan sebagian besar praktik pemberian MP-ASI yang dilakukan belum sesuai yaitu sebanyak 69,4\%.

b) Praktik Pemberian MP-ASI Setelah Perlakuan

\begin{tabular}{llrr}
\hline No & Praktik Pemberian MP-ASI & f & \% \\
\hline 1 & Sesuai & 37 & 52.8 \\
2 & Tidak Sesuai & 35 & 47.2 \\
& & 72 & 100.0 \\
\hline
\end{tabular}

Berdasarkan tabel 4.3 menunjukan bahwa dari 72 responden setelah diberikan pendidikan kesehatan sebagian besar praktik pemberian MP-ASI yang dilakukan telah sesuai yaitu sebanyak $52,8 \%$.

c) Uji Normalitas Data

\begin{tabular}{llcc}
\hline No & Data & KolmogorovSmirnov & Shapiro Wilk \\
\hline 1 & Pre Test & 0.000 & 0.000 \\
2 & Post Test & 0.000 & 0.000 \\
\hline
\end{tabular}

Berdasarkan Tabel 4.4 menunjukan bahwa hasil uji normalitas data dengan menggunakan uji Shapiro wilk diperoleh nilai $\mathrm{p}$ value sebelum dan sesudah diberikan pendidikan kesehatan adalah 0.000 atau $<0,05$, sehingga uji analisa bivariat yang akan digunakan dalam penelitian ini adalah uji wilcoxon.

b. Analisa Data Bivariat

Tabel 4.5

Perbedaan Kesesuaian Pemberian MP-ASI Sebelum dan Sesudah di Berikan Pendidikan Kesehatan Pada Ibu Yang Memiliki Bayi Usia 6-12 Bulan di Wilayah Kerja Puskesmas Baitussalam Aceh Besar

\begin{tabular}{ccccc}
\hline Variabel & \multicolumn{2}{c}{ Mean } & \multicolumn{2}{c}{ Std. Deviation } \\
\cline { 2 - 5 } & Pre Test & Post Test & Pre Test & Post Test \\
\hline $\begin{array}{c}\text { Kesesuaian } \\
\text { Pemberian MP- } \\
\text { ASI }\end{array}$ & 2.75 & 3.15 & 1.031 & 1.070 \\
\hline
\end{tabular}

Berdasarkan hasil uji wilcoxon diperoleh hasil keseuaian pemberian MP-ASI sesudah diberikan pendidikan kesehatan lebih tinggi yaitu sebesar 3.15 dibandingkan dengan kesesuaian pemberian MP-ASI sebelum diberikan pendidikan kesehatan yaitu sebesar 2.75 . 
Tabel 4.5

Hasil Uji Wilcoxon dengan menggunakan Software SPSS 16.0 For Windows

\begin{tabular}{|ll|c|c|c|}
\hline & & N & Mean Rank & $\begin{array}{c}\text { Sum of } \\
\text { Ranks }\end{array}$ \\
\hline & Negative Ranks & $17^{\mathrm{a}}$ & 26.88 & 457.00 \\
Post test - Pretest & Positive Ranks & $35^{\mathrm{b}}$ & 26.31 & 921.00 \\
& $\begin{array}{c}\text { Ties } \\
\text { Total }\end{array}$ & $20^{\mathrm{c}}$ & & \\
\hline
\end{tabular}
a. Post Test $<$ Pre Test
b. Post Test $>$ Pre Test
c. Post Test $=$ Pre Test

Berdasarkan tabel 4.5 menunjukan bahwa nilai negative ranks adalah 17 yang berarti bahwa jumlah sampel yang nilai posttestnya lebih rendah dari nilai pretes adalah sebanyak 17 orang. Positive Ranks adalah 35 yang berarti jumlah sampel yang nilai postestnya lebih besar dari nilai pretes adalah sebanyak 35 orang dan nilai Ties adalah 20 yang berarti jumlah sampel yang memiliki nilai post test yang sama dengan nilai pretes adalah sebanyak 20 orang.

Tabel 4.6

Hasil Uji Statistik dengan Menggunakan Uji Wilcoxon Signed Rank Test

\begin{tabular}{|l|rr|}
\hline & \multicolumn{2}{|c|}{ Post Test - Pre Test } \\
\hline$Z$ & & $-2.157^{\mathrm{b}}$ \\
Asymp. Sig. (2-tailed) & .031 \\
\hline
\end{tabular}

a. Wilcoxon Signed Rank Test

b. Based on negative rank

Berdasarkan hasil dari perhitungan Wilcoxon Signed Rank Test, maka nilai Z yang didapat sebesar -2,157 dengan p value (Asymp. Sig 2 tailed) sebesar 0,031 di mana kurang dari batas kritis penelitian 0,05 sehingga keputusan hipotesis adalah menerima $\mathrm{H} 1$ atau yang berarti terdapat perbedaan bermakna antara kelompok pretest dan posttest atau dapat disimpulkan bahwa ada perbedaan praktik pemberian MP-ASI sebelum dan sesudah diberikan pendidikan kesehatan.

\section{PEMBAHASAN}

Berdasarkan hasil penelitian diperolah bahwa sebelum diberikan pendidikan kesehatan ibu yang memberikan MP-ASI sesuai dengan rekomendasi dari WHO kepada bayi usia 6-12 bulan adalah sebanyak 30,6\%, sedangkan setelah diberikan pendidikan kesehatan tentang MP-ASI yang tepat dan sesuai dengan rekomendasi dari WHO jumlah ibu yang memberikan MP-ASI sesuai ke pada bayi usia 6-12 bulan meningkat menjadi 52,8\%.

Hasil analisis menggunakan Uji Wilcoxon Signed Rank Test diperoleh bahwa kesesuaian pemberian MPASI sesudah diberikan pendidikan kesehatan lebih tinggi yaitu sebesar 3.15 dibandingkan dengan kesesuaian pemberian MP-ASI sebelum diberikan pendidikan kesehatan yaitu sebesar 2.75. Hal ini menunjukan adanya peningkatan pemberian MP-ASI yang tepat dan 
sesuai sebelum dan sesudah pemberian pendidikan kesehatan. Hasil uji statistic diperoleh nilai pvalue $=0,031(\mathrm{p}<0,05)$, sehingga dapat disimpulkan bahwa ada perbedaan yang signifikans antara kesesuaian pemberian MP-ASI pada bayi usia 6-12 bulan sebelum dan sesudah diberikan pendidikan kesehatan.

Hasil penelitian ini sejalan dengan hasil penelitian yang dilakukan oleh Pradanan (2012) yang menunjukan bahwa jumlah praktik pemberian MP-ASI kurang mengalami penurunan dari 18 responden $(54,5 \%)$ sebelum kader memberikan pendidikan kesehatan menjadi 11 responden $(33,3 \%)$ setelah kader memberikan pendidikan kesehatan. Ibu yang memiliki praktik pemberian MP-ASI baik juga meningkat dari 15 responden $(45,5 \%)$ sebelum diberikan pendidikan kesehatan menjadi 22 responden $(66,7 \%)$ setelah diberikan pendidikan kesehatan. Hasil uji statistic diperoleh nilai $\mathrm{p}=0,01(\mathrm{P}<0,05)($ Dhita, 2012)

Hasil penelitian yang dilakukan oleh Saleem et al (2014) di Karachi, Pakistan mengenai pengaruh edukasi gizi pada ibu tentang MP-ASI terhadap status gizi anak, yang dilakukan selama 30 minggu, memberikan dampak positif pada penambahan berat badan, tinggi badan dan lingkar lengan atas, serta menurunkan prevalensi stunting dan gizi kurang sebesar 10\% pada kelompok yang diberikan edukasi tersebut. Jika pengetahuan dan perilaku ibu tentang pemberian MP-ASI baik, seimbang dan mencukupi kebutuhan gizi anak maka akan berdampak positif terhadap status gizi anak sehingga dapat mencegah terjadinya malnutrisi.

Pendidikan kesehatan pada hakikatnya merupakan suatu kegiatan atau usaha menyampaikan pesan kesehatan kepada masyarakat atau individu. Dengan harapan bahwa dengan adanya pesan tersebut, kelompok atau individu dapat memperoleh pengetahuan tentang kesehatan yang lebih baik. Pengetahuan tersebut pada akhirnya diharapkan dapat berpengaruh terhadap perilaku. Dengan kata lain dengan adanya promosi kesehatan tersebut, diharapkan dapat membawa akibat terhadap perubahan perilaku dari sasaran. Didalam suatu proses pendidikan kesehatan yang menuju tercapainya tujuan promosi (Notoatmodjo, 2011). Peran petugas kesehatan dalam memberikan penyuluhan MP-ASI juga terbukti dapat meningkatkan pola pikir dan tingkat kepedulian ibu untuk memberikan asupan makanan yang baik, bahkan jika perlu ditambahkan praktik cara pembuatan MP-ASI supaya perilaku pemberian MP-ASI menjadi tepat secara jumlah dan jenisnya (Arini FA, 2017).

Berdasarkan asumsi peneliti banyaknya ibu yang tidak memberikan MP-ASI yang tepat dan sesuai ke pada bayi nya salah satunya disebabkan oleh kurangnya pengetahuan tentang MPASI meliputi keberagaman zat gizi yang harus diberikan, jumlah takaran yang tepat untuk satu porsi pemberian, tekstur dan juga frekuensi pemberian MP-ASI kepada bayi sesuai dengan usianya. Hal ini terbukti saat peneliti mengumpulkan data dengan wawancara langsung terhadap responden, sebagian besar responden mengatakan tidak tahu tentang MP-ASI yang sesuai dengan rekomendasi dari WHO dan selama ini responden memberikan MP-ASI berdasarkan pengalaman pemberian MP-ASI yang didapatkan dari orang tua atau teman2nya. Hal ini menyebabkan banyak bayi yang tidak mendapatkan MP-ASI yang tepat dan sesuai yang pada akhirnya akan berdampak pada status gizi mereka sehingga banyak balita di wilayah kerja puskesmas Baitussalam mengalami masalah gizi yaitu stunting.

Setelah pemberian pendidikan kesehatan tentang MP-ASI yang tepat dan sesuai dengan rekomendasi dari WHO, ternyata ada peningkatan jumlah ibu yang memberikan MP-ASI yang sesuai kepada bayinya. Sehingga peneliti menarik kesimpulan bahwa pendidikan kesehatan sangat penting dilakukan untuk meningkatkan pengetahuan dan kemauan ibu agar dapat meberikan MPASI yang tepat kepada bayinya. Harapan terbesar dari perubahan perilaku setelah diberikan 
pendidikan kesehatan ini adalah seluruh ibu mampu memberikan MP-ASI yang tepat dan sesuai kepada bayinya sehingga jumlah angka stunting dapat berkurang dan teratasi dengan maksimal.

\section{KESIMPULAN}

Berdasarkan hasil penelitian yang di lakukan di Wilayah Kerja Puskesmas Baitussalam Aceh Besar terhadap Ibu yang memiliki bayi Usia 6-12 bulan maka dapat di simpulkan bahwa:

1. Kesesuaian pemberian MP-ASI Pada ibu yang memiliki bayi Usia 6-12 bulan sebelum diberikan pendidikan kesehatan adalah sebesar 2,75

2. Kesesuaian pemberian MP-ASI Pada ibu yang memiliki bayi Usia 6-12 bulan sesudah diberikan pendidikan kesehatan adalah sebesar 3,15

3. Adanya peningkatan kesesuaian pemberian MP-ASI pada ibu yang memiliki bayi Usia 6-12 bulan dengan nilai $\mathrm{p}=0,031$.

\section{SARAN}

Diharapkan kepada petugas kesehatan khusunya petugas Puskesmas dan Posyandu agar dapat memberikan penyuluhan dan pendidikan kesehatan yang lebih baik lagi kepada ibu yang memiliki bayi usia 6-12 tentang pemberian MP-ASI yang tepat dan sesuai agar kebutuhan gizi bagi anak menjadi optimal sesuai dengan usia pertumbuhannya sehingga dapat mencegah permasalah gizi yang selama ini dihadapi salah satunya adalah stunting.

\section{DAFTAR PUSTAKA}

Arini FA, Sofianita NI, Bahrul Ilmi IM. Pengaruh Pelatihan Pemberian MP ASI Kepada Ibu dengan Anak Baduta Di Kecamatan Sukmajaya Kota Depok Terhadap Pengetahuan dan Perilaku Pemberian MP ASI. J Kedokt dan Kesehat. 2017;13(1):80.

Dinas Kesehatan Aceh. Profil Kesehatan Aceh 2018. Profil Kesehatan Aceh. 2018;(9):196.

Direktorat Bina Gizi Masyarakat. Modul Konseling MP-ASI. Jakarta: Kementerian Kesehatan RI; 2010.

Dhita, P. A. Pengaruh Pendidikan Kesehatan Oleh Kader Terhadap Praktek Ibu dalam Pemberian MP-ASI di Wilayah Kerja Puskesmas Ledokombo Kabupaten Jember. repository.unej.ac.id. 2012 : 85

Hasdianah, Sandu Siyoto YP. Gizi, Pemantapan Gizi, Diet dan Obesitas. Yogyakarta: Nuha Medika; 2014.

Kurniasih, D; Hilmansyah, H; Astuti, MP; Imam S 2010. Sehat dan Bugar Berkat Gizi Seimbang. Soekirman AN\& EJN\& YIDI, editor. Jakarta: PT Penerbitan Sarana Bobo;

Notoatmodjo S. Kesehatan Masyarakat Ilmu dan Seni. Jakarta: Rineka Cipta; 2011.

Riskesdas. Hasil Utama Riset Kesehatan Dasar Tahun 2018. Kementrian Kesehatan Republik Indonesia. 2018;1-100.

Saleem AF, Mahmud S, Baig-Ansari N, Zaidi AKM. Impact of Maternal Education about Complementary 
Feeding on Their Infants' Nutritional Outcomes in Low- and Middle-income Households: A Community-based Randomized Interventional Study in Karachi, Pakistan. J Heal Popul Nutr. 2014;32(4):623-33.

Sitompul EM. Buku Pintar MPASI : Bayi 6 Bulan Sampai Dengan 1 Tahun. Jakarta: Arena Kids; 2014.

Suwardi. Jumlah Penderita Stunting. Aceh Besar: Puskesmas Baitussalam Aceh Besar; 2020.

Uun Kunaepah, Alina Hizni, Aniz Abdul Muiz, Sulstiyono P PS. Panduan Praktis Memberi Makan Bayi 612 Bulan. Sulistiyono P, editor. Kendal: Ernest; 2018. 3 p.

Waryana. Gizi Reproduksi. Yogyakarta: Pustaka Rihama; 2010. 